\title{
PENGARUH TEKANAN PEKERJAAN DAN STRES PEKERJAAN TERHADAP EVALUASI KINERJA
}

\author{
Jerry M. Logahan \\ Jurusan Manajemen, Fakultas Ekonomi dan Bisnis, Universitas Bina Nusantara, \\ Jln. K.H. Syahdan No. 9, Palmerah, Jakarta Barat 11480 \\ jlogahan@yahoo.com
}

\begin{abstract}
The lawyer profession at this time has become the public spotlight due to their role in upholding justice and defending the oppressed. This noble work requires reliable performance. Therefore, performance evaluation of lawyers needs to be considered. Factors that affect the performance evaluation of lawyers should also be investigated further. The purpose of this study is to see the correlation of job stress and pressure of work on performance evaluation of the lawyers, especially in corporate law firm "H H. Harris Sarana and Partner Law Firm". This research has shown that the effects of job stress and job stress have a significant impact on performance evaluation. Work pressure variable can affect performance evaluation significantly. With the situation now, corporate leaders need to consider the pressures of work and working atmosphere, so performance can be increased. In addition, companies need to improve communications systems and trying to minimize all forms of work stressors, so the lawyers can provide more optimal results in doing their job.
\end{abstract}

Keywords: job, pressure, stressor, performance, evaluation

\begin{abstract}
ABSTRAK
Tugas sebagai pengacara saat ini menjadi sorotan masyarakat karena perannya dalam menegakkan keadilan dan membela yang tertindas. Pekerjaan yang mulia ini membutuhkan kinerja yang dapat dipertanggung jawabkan. Oleh karena itu, evaluasi kinerja para pengacara perlu diperhatikan. Hal-hal yang mempengaruhi evaluasi kinerja para pengacara perlu juga diteliti lebih jauh. Tujuan penelitian adalah untuk melihat pengaruh stres pekerjaan dan tekanan pekerjaan terhadap evaluasi kinerja dari para pengacara, khususnya di perusahaan hukum "H. Harris Sarana SH and Partners". Dari penelitian, didapatkan bahwa pengaruh tekanan pekerjaan dan stres pekerjaan cukup mempengaruhi evaluasi kinerja. Variabel tekanan pekerjaan dapat mempengaruhi evaluasi kinerja secara signifikan. Dengan keadaan sekarang, pimpinan perusahaan perlu memperhatikan tekanan pekerjaan dan suasana kerja, agar lebih dapat meningkatkan evaluasi kinerja para pengacara. Selain itu, perusahaan perlu memperbaiki sistem komunikasi dan berusaha meminimalisasi segala bentuk stressor kerja, agar para pengacara dapat memberikan hasil yang lebih optimal dalam melakukan pekerjaannya.
\end{abstract}

Kata kunci: pekerjaan, tekanan, stres, kinerja, evaluasi 


\section{PENDAHULUAN}

Tugas sebagai pengacara saat ini menjadi sorotan masyarakat karena perannya dalam menegakkan keadilan dan membela yang tertindas. Pekerjaan yang mulia ini membutuhkan kinerja yang dapat dipertanggung jawabkan. Oleh karena itu, evaluasi kinerja para pengacara perlu diperhatikan serta hal-hal yang mempengaruhi evaluasi kinerja para pengacara perlu ditarik suatu benang merahnya. Untuk itulah penulis ingin melihat pengaruh stres pekerjaan dan tekanan pekerjaan terhadap evaluasi kinerja dari para pengacara, khususnya di perusahaan hukum "H. Harris Sarana SH and Partners".

Peneliti mengetahui beberapa permasalahan yang perlu dikaji, di antaranya (1) Apakah ada pengaruh tekanan pekerjaan terhadap evaluasi kinerja para pengacara pada law firm $\mathrm{H}$. Harris Sarana, SH and Partners?; (2) Apakah ada pengaruh stres pekerjaan terhadap evaluasi kinerja para pengacara pada law firm H. Harris Sarana, SH and Partners?; dan (3) Apakah ada pengaruh tekanan pekerjaan dan stres pekerjaan terhadap evaluasi kinerja para pengacara pada law firm $\mathrm{H}$. Harris Sarana, SH and Partners?.

\section{METODE PENELITIAN}

Tujuan dilakukannya penelitian ini adalah karena peneliti ingin mengetahui hubungan antara tekanan pekerjaan dengan stres yang diterima dari pekerjaan terhadap evaluasi kinerja para pengacara yang berada di bawah naungan H. Harris Sarana, SH and Partners. Untuk mendapatkan data yang dibutuhkan, penulis melakukan serangkaian proses yang dibutuhkan dalam mencari dan mengumpulkan data agar sesuai dengan kondisi yang sesungguhnya terjadi (Tabel 1). Sementara itu, kerangka pemikiran dapat dilihat pada Gambar 1.

Tabel 1 Desain Penelitian

\begin{tabular}{ccccc}
$\begin{array}{c}\text { Tujuan } \\
\text { Penelitian }\end{array}$ & $\begin{array}{c}\text { Jenis } \\
\text { Penelitian }\end{array}$ & $\begin{array}{c}\text { Metode } \\
\text { Penelitian }\end{array}$ & $\begin{array}{c}\text { Unit } \\
\text { Analisa }\end{array}$ & $\begin{array}{c}\text { Time } \\
\text { Horizon }\end{array}$ \\
\hline T-1 & Asosiatif & Survei & Individu-Pengacara & Cross-Sectional \\
T-2 & Asosiatif & Survei & Individu-Pengacara & Cross-Sectional \\
T-3 & Asosiatif & Survei & Individu-Pengacara & Cross-Sectional \\
\hline
\end{tabular}

Keterangan:

T-1 : Mengetahui hubungan antara tekanan pekerjaan terhadap evaluasi kinerja para pengacara yang berada di bawah naungan H. Harris Sarana, SH and Partners.

T-2 : Mengetahui hubungan antara stres yang diterima dari pekerjaan terhadap evaluasi kinerja para pengacara yang berada di bawah naungan H. Harris Sarana, SH and Partners.

T-3: Mengetahui hubungan antara tekanan pekerjaan dengan stres yang diterima dari pekerjaan terhadap evaluasi kinerja para pengacara yang berada di bawah naungan H. Harris Sarana, SH and Partners. 


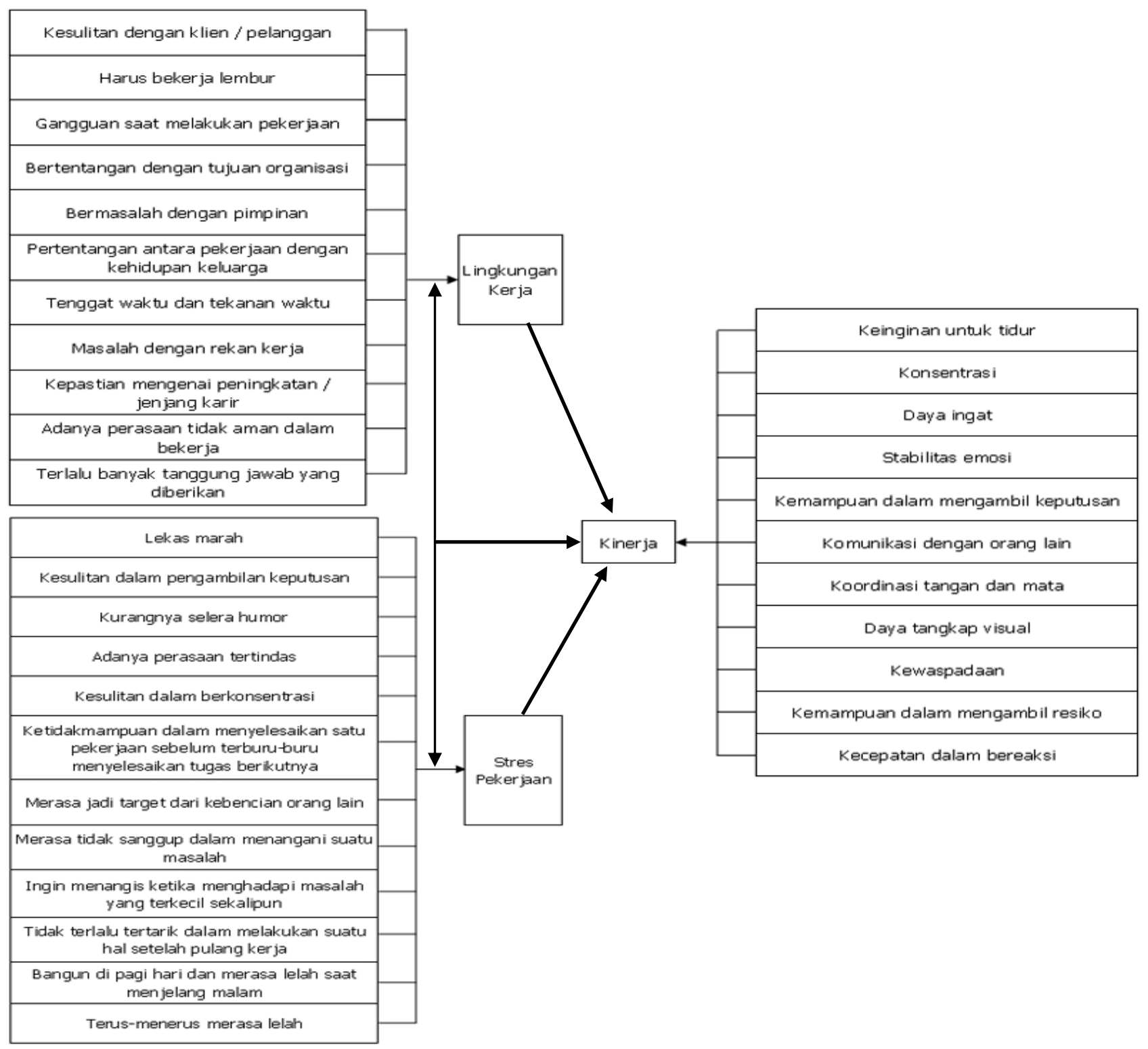

Gambar 1 Kerangka Pemikiran

\section{HASIL DAN PEMBAHASAN}

\section{Uji Validitas}

Hasil uji validitas penelitian ini dapat dilihat pada Tabel 1, 2, dan 3. 
Tabel 1 Uji Validitas Pernyataan Variabel $\mathrm{X}_{1}$ (Tekanan Pekerjaan)

\begin{tabular}{cccc}
\hline Variabel & $\begin{array}{c}\text { Koefisien } \\
\text { Korelasi }\end{array}$ & $\mathbf{R}_{\text {tabel }}$ & Validitas \\
\hline X1_1 & 0,712 & 0,55 & Valid \\
X1_2 & 0,738 & 0,55 & Valid \\
X1_3 & 0,761 & 0,55 & Valid \\
X1_4 & 0,623 & 0,55 & Valid \\
X1_5 & 0,605 & 0,55 & Valid \\
X1_6 & 0,659 & 0,55 & Valid \\
X1_7 & 0,611 & 0,55 & Valid \\
X1_8 & 0,632 & 0,55 & Valid \\
X1_9 & 0,676 & 0,55 & Valid \\
X1_10 & 0,617 & 0,55 & Valid \\
X1_11 & 0,676 & 0,55 & Valid \\
X1_12 & 0,665 & 0,55 & Valid \\
\hline
\end{tabular}

Sumber: Data Kuesioner Variabel $\mathrm{X}_{1}$

(Tekanan Pekerjaan) yang diolah dengan SPSS

Tabel 2 Uji Validitas Pernyataan Variabel $\mathrm{X}_{2}$ (Stres Pekerjaan)

\begin{tabular}{cccc}
\hline Variabel & $\begin{array}{c}\text { Koefisien } \\
\text { Korelasi }\end{array}$ & $\mathbf{R}_{\text {tabel }}$ & Validitas \\
\hline X2_1 & 0,655 & 0,55 & Valid \\
X2_2 & 0,683 & 0,55 & Valid \\
X2_3 & 0,697 & 0,55 & Valid \\
X2_4 & 0,667 & 0,55 & Valid \\
X2_5 & 0,617 & 0,55 & Valid \\
X2_6 & 0,662 & 0,55 & Valid \\
X2_7 & 0,637 & 0,55 & Valid \\
X2_8 & 0,605 & 0,55 & Valid \\
X2_9 & 0,676 & 0,55 & Valid \\
X2_10 & 0,659 & 0,55 & Valid \\
X2_11 & 0,647 & 0,55 & Valid \\
X2_12 & 0,642 & 0,55 & Valid \\
\hline Sumber: Data Kuesioner Variabel X $($ Stres Pekerjaan) \\
yang diolah dengan SPSS
\end{tabular}


Tabel 3 Uji Validitas Pernyataan Variabel $\mathrm{X}_{3}$ (Evaluasi Kinerja)

\begin{tabular}{cccc}
\hline Variabel & $\begin{array}{c}\text { Koefisien } \\
\text { Korelasi }\end{array}$ & $\mathbf{R}_{\text {tabel }}$ & Validitas \\
\hline Y_1 & 0,621 & 0,55 & Valid \\
Y_2 & 0,677 & 0,55 & Valid \\
Y_3 & 0,622 & 0,55 & Valid \\
Y_4 & 0,659 & 0,55 & Valid \\
Y_5 & 0,662 & 0,55 & Valid \\
Y_6 & 0,655 & 0,55 & Valid \\
Y_7 & 0,687 & 0,55 & Valid \\
Y_8 & 0,659 & 0,55 & Valid \\
Y_9 & 0,694 & 0,55 & Valid \\
Y_10 & 0,671 & 0,55 & Valid \\
\hline
\end{tabular}

Sumber: Data Kuesioner Variabel $\mathrm{X}_{3}$

(Evaluasi Kinerja) yang diolah dengan SPSS

Uji validitas untuk tiap pernyataan dilakukan dengan menggunakan rumus korelasi Pearson Product Moment, dengan mengkorelasikan nilai dari setiap pernyataan. Dasar pengambilan keputusan pada uji validitas ini adalah sebagai berikut. Jika Koefisien Korelasi $\left(\mathrm{R}_{\text {hitung }}\right)>0,55\left(\mathrm{R}_{\text {tabel }}\right)$, maka pernyataan tersebut valid, dan jika Koefisien Korelasi $\left(\mathrm{R}_{\text {hitung }}\right)<0,55\left(\mathrm{R}_{\text {tabel }}\right)$, maka pernyataan tersebut tidak valid. Berdasarkan ketiga tabel di atas, seluruh pernyataan pada Variabel X1 (tekanan pekerjaan), X2 (stress pekerjaan), $\mathrm{X}_{3}$ (Evaluasi Kinerja) adalah valid, karena Koefisien Korelasi $\left(\mathrm{R}_{\text {hitung }}\right)>0,55\left(\mathrm{R}_{\text {tabel }}\right)$.

\section{Uji Reliabilitas}

Uji realibilitas digunakan untuk mengukur tingkat keakuratan kuesioner dan uji realibilitas yang digunakan di dalam penelitian ini adalah realibilitas dengan metode Alpha. Pada teknik Alpha, Cronbach's Alpha didapat dari hasil perhitungan varians yang dimasukkan ke rumus Alpha. Nilai $\mathrm{R}_{\text {tabel }}$ dilihat dari tabel R di Product Moment, dengan df (degree of freedom) : n-2, dan untuk penelitian ini, df : $10-2=8$, dengan tingkat kepercayaan $95 \%$ dan nilai $\mathrm{R}_{\text {tabel }}$ adalah 0,55 .

Dasar pengambilan keputusan untuk uji realibilitas ini adalah sebagai berikut:

Jika Cronbach's Alpha $>0,55\left(\mathrm{R}_{\text {tabel }}\right)$, maka kuesioner yang diuji bersifat reliabel. Sedangkan, jika Cronbach's Alpha $<0,55\left(\mathrm{R}_{\text {tabel }}\right)$, maka kuesioner yang diuji bersifat tidak reliabel.

Tabel 4 Uji Reliabilitas Pernyataan Variabel $X_{1}$ (Tekanan Pekerjaan)

\begin{tabular}{cccc}
\hline Variabel & Cronbach's Alpha & $\mathbf{R}_{\text {tabel }}$ & Reliabilitas \\
\hline Tekanan Pekerjaan & 0,602 & 0,55 & Reliabel \\
\hline \multicolumn{3}{c}{ Sumber: Data Kuesioner Variabel X P $_{1}$} \\
(Tekanan pekerjaan) yang diolah dengan SPSS
\end{tabular}

Berdasarkan tabel di atas, maka telah terbukti bahwa semua pernyataan pada variabel tekanan pekerjaan bersifat reliabel karena nilai Cronbach's Alpha $(0,602)>$ daripada $\mathrm{R}_{\text {tabel }}(0,55)$. 
Tabel 5 Uji Reliabilitas Pernyataan Variabel $\mathrm{X}_{2}$ (Stres Pekerjaan)

\begin{tabular}{cccc}
\hline Variabel & Cronbach's Alpha & $\mathbf{R}_{\text {tabel }}$ & Reliabilitas \\
\hline \multirow{2}{*}{ Stres Pekerjaan } & 0,602 & 0,55 & Reliabel \\
\hline
\end{tabular}

Sumber: Data Kuesioner Variabel $\mathrm{X}_{2}$

(Stres Pekerjaan) yang diolah dengan SPSS

Berdasarkan tabel di atas, maka telah terbukti bahwa semua pernyataan pada variabel stres pekerjaan adalah bersifat reliabel karena nilai Cronbach's Alpha $(0,602)>$ daripada $\mathrm{R}_{\text {tabel }}(0,55)$.

Tabel 6 Uji Validitas Reliabilitas Pernyataan Variabel $\mathrm{X}_{3}$ (Evaluasi Kinerja)

\begin{tabular}{cccc}
\hline Variabel & Cronbach's Alpha & $\mathbf{R}_{\text {tabel }}$ & Reliabilitas \\
\hline Evaluasi Kinerja & 0,602 & 0,55 & Reliabel \\
\hline
\end{tabular}

Sumber: Data Kuesioner Variabel $\mathrm{X}_{3}$

(Kinerja Pengacara) yang diolah dengan SPSS

Berdasarkan tabel di atas, maka telah terbukti bahwa semua pernyataan pada variabel evaluasi kinerja bersifat reliabel karena nilai Cronbach's Alpha $(0,602)>$ daripada $\mathrm{R}_{\text {tabel }}(0,55)$. Kesimpulannya adalah seluruh pernyataan yang terdapat di kuesioner yang digunakan di dalam penelitian ini bersifat reliabel karena nilai Cronbach's Alpha $>$ daripada $R_{\text {tabel. }}$. Hal ini menunjukkan bahwa alat ukur akurat dan dapat dipercaya kebenarannya.

\section{Analisis Korelasi Bivariate}

Analisis korelasi bivariate adalah analisis hubungan antar variabel, yaitu erat atau tidaknya hubungan, arah hubungan, dan berarti atau tidaknya suatu hubungan. Berikut ini adalah analisis korelasi bivariate antara variabel tekanan pekerjaan, stres pekerjaan, dan evaluasi kinerja (Tabel 7).

Tabel 7 Uji Korelasi Bivariate Variabel

Tekanan Pekerjaan dengan Stres Pekerjaan

Correlations

\begin{tabular}{|ll|r|r|}
\hline & & $\begin{array}{c}\text { Lingkungan_ } \\
\text { Kerja }\end{array}$ & $\begin{array}{c}\text { Stres__an } \\
\text { Pekerjaan }\end{array}$ \\
\hline Lingkungan_Kerja & Pearson Correlation & 1 & $-.735^{\prime \prime}$ \\
& Sig. (2-tailed) & 12 & .006 \\
& $\mathrm{~N}$ & $-.735^{\prime \prime}$ & 12 \\
\hline Stres_Pekerjaan & Pearson Correlation & .006 & 1 \\
& Sig. (2-tailed) & 12 & 12 \\
& $\mathrm{~N}$ & & \\
\hline
\end{tabular}

*. Correlation is significant at the 0.01 level (2-tailed)

Dari analisis korelasi di atas, didapat koefisien korelasi yang digunakan untuk mengetahui keeratan hubungan dan arah hubungan, sedangkan signifikansi untuk mengetahui apakah hubungan yang terjadi, berarti atau tidak. Untuk mengetahui keeratan hubungan, maka dapat dilihat dari besarnya koefisien korelasi dengan pedoman, yaitu jika koefisien korelasi semakin mendekati 1 atau 1, maka hubungan erat atau kuat, sedangkan jika koefisien korelasi semakin mendekati 0 , maka hubungan lemah. Untuk mengetahui arah hubungan, maka dapat dilihat pada tanda nilai koefisien, yaitu positif dan negatif. 
Dari output di atas, didapat koefisien korelasi antara tekanan pekerjaan dengan stres pekerjaan adalah $-0,735$. Karena nilai lebih mendekati 1 , maka hubungan antara tekanan pekerjaan dengan stres pekerjaan adalah erat dan kuat. Nilai koefisien bertanda negatif, yang berarti hubungan negatif. Artinya adalah jika tekanan pekerjaan buruk, maka stres pekerjaan akan meningkat; atau jika tekanan pekerjaan baik, maka stres pekerjaan akan menurun.

Untuk mengetahui hubungan berarti atau tidak, maka dilakukan pengujian signifikansi sebagai berikut (1) Menentukan hipotesis $\mathrm{H}_{0}$ dan $\mathrm{H}_{1}$, yakni $\mathrm{H}_{0}$ adalah tidak ada hubungan antara tekanan pekerjaan dengan stres pekerjaan dan $\mathrm{H}_{1}$ adalah ada hubungan antara tekanan pekerjaan dengan stres pekerjaan; (2) Menentukan signifikansi. Dari output, dapat diketahui signifikansi adalah 0,006; (3) Pengambilan keputusan, yakni signifikansi $>0,05$, maka $\mathrm{H}_{0}$ diterima dan signifikansi $\leq 0,05$, maka $\mathrm{H}_{0}$ ditolak; (4) Kesimpulan. Signifikansi sebesar 0,006 $\leq 0,05$, maka $\mathrm{H}_{0}$ ditolak, kesimpulannya adalah ada hubungan yang berarti antara tekanan pekerjaan dengan stres pekerjaan.

Tabel 8 Uji Korelasi Bivariate Variabel Tekanan Pekerjaan dengan Evaluasi Kinerja

\begin{tabular}{|c|c|c|c|}
\hline \multicolumn{4}{|c|}{ Correlations } \\
\hline & & $\underset{\text { Kerja }}{\text { Lingkungan }}$ & $\begin{array}{l}\text { Kinerja } \\
\text { Pengacara }\end{array}$ \\
\hline Lingkungan_Kerja & $\begin{array}{l}\text { Pearson Correlation } \\
\text { Sig. (2-tailed) } \\
N\end{array}$ & $\begin{array}{r}1 \\
12\end{array}$ & $\begin{array}{r}.683^{\circ} \\
.030 \\
10\end{array}$ \\
\hline Kinerja_Pengacara & $\begin{array}{l}\text { Pearson Correlation } \\
\text { Sig. (2-tailed) } \\
N\end{array}$ & $\begin{array}{r}.683^{\prime} \\
.030 \\
10 \\
\end{array}$ & $\begin{array}{r}1 \\
10 \\
\end{array}$ \\
\hline
\end{tabular}

Dari output di atas, didapat koefisien korelasi antara tekanan pekerjaan dengan evaluasi kinerja adalah 0,683. Karena nilai lebih mendekati 1, maka hubungan antara tekanan pekerjaan dengan evaluasi kinerja adalah erat dan kuat. Nilai koefisien bertanda positif, yang berarti hubungan positif, artinya jika tekanan pekerjaan baik maka evaluasi kinerja akan meningkat, atau jika tekanan pekerjaan buruk maka evaluasi kinerja akan menurun.

Untuk mengetahui hubungan berarti atau tidak, maka dilakukan pengujian signifikansi sebagai berikut (1) Menentukan hipotesis $\mathrm{H}_{0}$ dan $\mathrm{H}_{1}$, yakni $\mathrm{H}_{0}$ adalah tidak ada hubungan antara tekanan pekerjaan dengan evaluasi kinerja dan $\mathrm{H}_{1}$ adalah ada hubungan antara tekanan pekerjaan dengan evaluasi kinerja; (2) Menentukan signifikansi. Dari output dapat diketahui signifikansi adalah 0,030; (4) Pengambilan keputusan, yakni signifikansi $>0,05$, maka $\mathrm{H}_{0}$ diterima dan signifikansi $\leq 0,05$, maka $\mathrm{H}_{0}$ ditolak; (4) Kesimpulan, yakni signifikansi sebesar $0,030 \leq 0,05$, maka $\mathrm{H}_{0}$ ditolak, kesimpulannya yaitu ada hubungan yang berarti antara tekanan pekerjaan dengan evaluasi kinerja.

Tabel 9 Uji Korelasi Bivariate Variabel

Stres Pekerjaan dengan Evaluasi Kinerja

Correlations

\begin{tabular}{|ll|r|r|}
\hline & & \multicolumn{1}{|c|}{$\begin{array}{c}\text { Stres_ } \\
\text { Pekerjaan }\end{array}$} & $\begin{array}{c}\text { Kinerja_ } \\
\text { Pengacara }\end{array}$ \\
\hline Stres_Pekerjaan & Pearson Correlation & 1 & $-.768^{\prime \prime}$ \\
& Sig. (2-tailed) & 12 & .009 \\
& $\mathrm{~N}$ & $-.768^{\prime \prime}$ & 10 \\
\hline Kinerja_Pengacara & Pearson Correlation & .009 & 1 \\
& Sig. (2-tailed) & 10 & 10 \\
& $\mathrm{~N}$ & & \\
\end{tabular}

*. Correlation is significant at the 0.01 level (2-tailed). 
Dari output di atas, didapat koefisien korelasi antara stres pekerjaan dengan evaluasi kinerja adalah $-0,768$. Karena nilai lebih mendekati 1, maka hubungan antara stres pekerjaan dengan evaluasi kinerja adalah erat dan kuat. Nilai koefisien bertanda negatif, yang berarti hubungan negative. Artinya adalah jika stres pekerjaan meningkat, maka dengan evaluasi kinerja akan menurun, atau jika stres pekerjaan menurun maka evaluasi kinerja akan meningkat.

Untuk mengetahui hubungan berarti atau tidak, maka dilakukan pengujian signifikansi sebagai berikut (1) Menentukan hipotesis $\mathrm{H}_{0}$ dan $\mathrm{H}_{1}$, yakni $\mathrm{H}_{0}$ adalah tidak ada hubungan antara stres pekerjaan dengan evaluasi kinerja dan $\mathrm{H}_{1}$ adalah ada hubungan antara stres pekerjaan dengan evaluasi kinerja; (2) Menentukan signifikansi. Dari output dapat diketahui signifikansi adalah 0,009; (3) Pengambilan keputusan, yakni signifikansi $>0,05$, maka $\mathrm{H}_{0}$ diterima dan signifikansi $\leq 0,05$, maka $\mathrm{H}_{0}$ ditolak; (4) Kesimpulan. Signifikansi sebesar $0,009 \leq 0,05$, maka $\mathrm{H}_{0}$ ditolak. Kesimpulannya adalah ada hubungan yang berarti antara stres pekerjaan dengan evaluasi kinerja.

\section{Analisis Koefisien Determinasi Regresi Sederhana}

Untuk mengetahui ada atau tidaknya pengaruh antara tekanan pekerjaan terhadap evaluasi kinerja, maka digunakan software SPSS, dengan perhitungan sebagai berikut ini:

Tabel 10 Variables Entered / Removed and Model Summary dari Tekanan Pekerjaan dengan Evaluasi Kinerja

\begin{tabular}{|l|l|l|l|}
\hline \begin{tabular}{|l|l|} 
Mode \\
\hline 1
\end{tabular} & $\begin{array}{c}\text { Variables } \\
\text { Entered }\end{array}$ & $\begin{array}{c}\text { Variables } \\
\text { Removed }\end{array}$ & Method \\
\hline & $\begin{array}{l}\text { Lingkungan_ } \\
\text { Kerja }\end{array}$ & . & Enter \\
\hline
\end{tabular}
a. All requested variables entered.
b. Dependent Variable: Kinerja_Pengacara

\begin{tabular}{|l|c|r|c|c|c|}
\hline Mode & $\mathrm{R}$ & $\mathrm{R}$ Square & $\begin{array}{c}\text { Adjusted R } \\
\text { Square }\end{array}$ & $\begin{array}{c}\text { Std. Error of } \\
\text { the Estimate }\end{array}$ & $\begin{array}{c}\text { Durbin- } \\
\text { Watson }\end{array}$ \\
\hline 1 & $.683^{\mathrm{a}}$ & .466 & .399 & .61466 & 2.300 \\
\hline
\end{tabular}
a. Predictors: (Constant), Lingkungan_Kerja
b. Dependent Variable: Kinerja_Pengacara

Hasil analisisnya adalah (1) Tabel variables entered/removed, tidak terdapat variables removed, yang berarti variabel bebas dimasukkan ke dalam perhitungan regresi; (2) R Square pada tabel Model Summary adalah 0,466 , yang berarti evaluasi kinerja dapat dipengaruhi oleh tekanan pekerjaan sebanyak dan sisanya sebesar 53,4\% (100\% - 46,6\%) dipengaruhi oleh faktor lain; (3) Standart error of estimate sebesar 0,61466 , di mana semakin kecil standart error of estimate, maka berarti model regresi semakin tepat dalam memprediksi variabel bebas; (4) R pada tabel Model Summary adalah 0,683 , yang berarti korelasi antara tekanan pekerjaan dengan evaluasi kinerja sebesar 0,683.

\section{Analisis Anova dan Koefisien Regresi Sederhana}

Berikut adalah hasil perhitungan dengan software SPSS (Tabel 11). 
Tabel 11 Anova and Coefficients

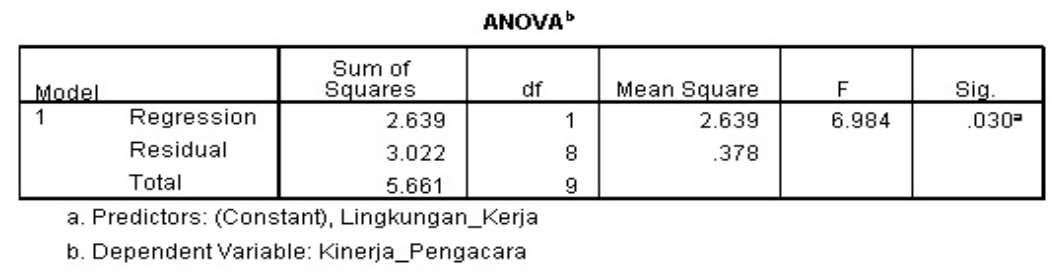

\begin{tabular}{|c|c|c|c|c|c|c|c|c|}
\hline \multicolumn{9}{|c|}{ Coefficients $^{\mathrm{a}}$} \\
\hline \multirow[b]{2}{*}{ Model } & & \multicolumn{2}{|c|}{ Unstandardized Coefficients } & \multirow{2}{*}{$\begin{array}{c}\begin{array}{c}\text { Standardized } \\
\text { Coefficients }\end{array} \\
\text { Beta } \\
\end{array}$} & \multirow[b]{2}{*}{$t$} & \multirow[b]{2}{*}{ Sig. } & \multicolumn{2}{|c|}{ Collinearity Statistics } \\
\hline & & B & Std. Error & & & & Tolerance & $\mathrm{VIF}$ \\
\hline \multirow[t]{2}{*}{1} & (Constant) & .748 & 1.048 & & .714 & .495 & & \\
\hline & Lingkungan_Kerja & .769 & .291 & .683 & 2.643 & .030 & 1.000 & 1.000 \\
\hline
\end{tabular}

Hasil analisisnya adalah (1) Signifikan di tabel Anova bernilai 0,030, yang $\leq$ dari 0,05, berarti tekanan pekerjaan berpengaruh terhadap evaluasi kinerja; (2) Hipotesis yakni $\mathrm{H}_{0}$ adalah tekanan pekerjaan tidak berpengaruh signifikan terhadap evaluasi kinerja dan $\mathrm{H}_{1}$ adalah tekanan pekerjaan berpengaruh signifikan terhadap evaluasi kinerja; (3) Dasar pengambilan keputusan yakni signifikansi $\geq 0,05$, maka $\mathrm{H}_{0}$ diterima dan signifikansi $\leq 0,05$, maka $\mathrm{H}_{0}$ ditolak; (4) Hasil perhitungannya adalah signifikan bernilai 0,030 , yang $\leq$ dari 0,05 , maka $\mathrm{H}_{0}$ ditolak dan berarti tekanan pekerjaan berpengaruh terhadap evaluasi kinerja secara signifikan; (5) Persamaan regresi di tabel Coefficient yakni $\mathrm{Y}=0,748+$ $0,769 \mathrm{x}_{1}$, di mana $\mathrm{Y}$ adalah evaluasi kinerja dan $\mathrm{x}_{1}$ adalah tekanan pekerjaan; (6) Pada persamaan regresi di atas, diketahui konstanta sebesar 0,748 , menyatakan bahwa jika tidak ada variabel tekanan pekerjaan, maka evaluasi kinerja nilainya sebesar 0,748; (7) Koefisien regresi sebesar 0,769 menyatakan bahwa setiap penambahan 1 angka, maka variabel tekanan pekerjaan akan meningkatkan evaluasi kinerja sebesar 0,769 .

\section{Analisis Koefisien Determinasi Regresi Sederhana}

Untuk mengetahui ada atau tidaknya pengaruh antara stres pekerjaan terhadap evaluasi kinerja, maka digunakan software SPSS, dengan perhitungan sebagai berikut ini (Tabel 12).

Tabel 12 Variables Entered/Removed and Model Summary dari Stres Pekerjaan dengan Evaluasi Kinerja

\begin{tabular}{|c|c|c|c|}
\hline \multicolumn{4}{|c|}{ Variables Entered/Removed ${ }^{\text {b }}$} \\
\hline Mode & $\begin{array}{c}\text { Variables } \\
\text { Entered }\end{array}$ & $\begin{array}{l}\text { Variables } \\
\text { Removed }\end{array}$ & Method \\
\hline 1 & $\begin{array}{l}\text { Stres } \\
\text { Pekerjaanz }\end{array}$ & & Enter \\
\hline
\end{tabular}

\begin{tabular}{|l|c|r|c|c|c|}
\hline Mode & $\mathrm{R}$ & R Square & $\begin{array}{c}\text { Adjusted R } \\
\text { Square }\end{array}$ & $\begin{array}{c}\text { Std. Error of } \\
\text { the Estimate }\end{array}$ & $\begin{array}{c}\text { Durbin- } \\
\text { Watson }\end{array}$ \\
\hline 1 & $.768^{2}$ & .590 & .539 & .53855 & 1.524 \\
\hline
\end{tabular}
a. Predictors: (Constant), Stres_Pekerjaan
b. Dependent Variable: Kinerja_Pengacara

Hasil analisisnya adalah (1) Tabel variables entered/removed, tidak terdapat variables removed, yang berarti variabel bebas dimasukkan ke dalam perhitungan regresi; (2) R Square pada tabel Model Summary adalah 0,590, yang berarti evaluasi kinerja dapat dipengaruhi oleh stres pekerjaan sebanyak 
$59,0 \%$ dan sisanya sebesar 41,0\% (100\% - 59,0\%) dipengaruhi oleh faktor lain; (3) Standart error of estimate sebesar 0,53855, di mana semakin kecil standart error of estimate, maka berarti model regresi semakin tepat dalam memprediksi variabel bebas; (4) R pada tabel Model Summary adalah 0,768 , yang berarti korelasi antara stres pekerjaan dengan evaluasi kinerja sebesar 0,768 .

\section{Analisis Anova dan Koefisien Regresi Sederhana}

Analisis anova dan koefisien regresi sederhana dapat dilihat pada Tabel 13 sebagai berikut.

Tabel 13 Anova and Coefficients

ANOVA $^{\mathrm{b}}$

\begin{tabular}{|ll|r|r|r|r|r|}
\hline Model & & $\begin{array}{c}\text { Sum of } \\
\text { Squares }\end{array}$ & df & Mean Square & F & Sig. \\
\hline 1 & Regression & 3.341 & 1 & 3.341 & 11.518 & $.00 g^{2}$ \\
& Residual & 2.320 & 8 & .290 & & \\
& Total & 5.661 & 9 & & & \\
\hline
\end{tabular}

a. Predictors: (Constant), Stres_Pekerjaan

b. Dependent Variable: Kinerja_Pengacara

\begin{tabular}{|c|c|c|c|c|c|c|c|c|}
\hline \multicolumn{9}{|c|}{ Coefficients $^{s}$} \\
\hline \multirow{2}{*}{\multicolumn{2}{|c|}{ Model }} & \multicolumn{2}{|c|}{ Unstandardized Coefficients } & \multirow{2}{*}{$\begin{array}{c}\begin{array}{c}\text { Standardized } \\
\text { Coefficients }\end{array} \\
\text { Beta } \\
\end{array}$} & \multirow[b]{2}{*}{$t$} & \multirow[b]{2}{*}{ Sig. } & \multicolumn{2}{|c|}{ Collinearity Statistics } \\
\hline & & B & Std. Error & & & & Tolerance & VIF \\
\hline \multirow[t]{2}{*}{1} & (Constant) & 6.172 & .814 & & 7.580 & .000 & & \\
\hline & Stres_Pekerjaan & -783 & 231 & -768 & -3.394 & 009 & 1000 & 1000 \\
\hline
\end{tabular}

Hasil analisisnya adalah (1) Signifikan di tabel Anova bernilai 0,009, yang $\leq$ dari 0,05 dan berarti bahwa stres pekerjaan berpengaruh terhadap evaluasi kinerja; (2) Hipotesis yakni $\mathrm{H}_{0}$ adalah stres pekerjaan tidak berpengaruh signifikan terhadap evaluasi kinerja dan $\mathrm{H}_{1}$ adalah stres pekerjaan berpengaruh signifikan terhadap evaluasi kinerja; (3) Dasar pengambilan keputusan yakni signifikansi $\geq 0,05$, maka $\mathrm{H}_{0}$ diterima dan signifikansi $\leq 0,05$, maka $\mathrm{H}_{0}$ ditolak; (4) Hasil perhitungannya adalah signifikan bernilai 0,009 , $\leq$ dari 0,05 , maka $\mathrm{H}_{0}$ ditolak dan berarti stres pekerjaan berpengaruh terhadap evaluasi kinerja secara signifikan; (5) Persamaan regresi di tabel Coefficient yakni $\mathrm{Y}=6,172$ - 0,783 $\mathrm{x}_{2}$, di mana $\mathrm{Y}$ adalah evaluasi kinerja dan $\mathrm{x}_{2}$ adalah stres pekerjaan; (6) Pada persamaan regresi di atas, diketahui konstanta sebesar 6,172, menyatakan bahwa jika tidak ada variabel stres pekerjaan, maka evaluasi kinerja nilainya sebesar 6,172; dan (7) Koefisien regresi sebesar -0,783, menyatakan bahwa setiap penambahan 1 angka, maka variabel stres pekerjaan akan menurunkan evaluasi kinerja sebesar 0,783 .

\section{Analisis Pengaruh Tekanan Pekerja dan Stres Pekerjaan terhadap Evaluasi Kinerja}

Analisis koefisien determinasi regresi sederhana dapat dilihat pada Tabel 14 sebagai berikut.

Tabel 14 Variables Entered/Removed and Model Summary dari Tekanan Pekerjaan dan Stres Pekerjaan dengan Evaluasi Kinerja

Variables Entered/Removed
\begin{tabular}{|l|l|l|l|}
\hline Mode & $\begin{array}{c}\text { Variables } \\
\text { Entered }\end{array}$ & $\begin{array}{c}\text { Variables } \\
\text { Removed }\end{array}$ & Method \\
\hline 1 & $\begin{array}{l}\text { Stres } \\
\text { Pekerjaan, } \\
\text { Lingkungan__ } \\
\text { Kerja }\end{array}$ & Enter \\
\hline
\end{tabular}
a. All requested variables entered.
b. Dependent Variable: Kinerja_Pengacara




\begin{tabular}{|c|c|c|c|c|c|}
\hline \multicolumn{6}{|c|}{ Model Summary ${ }^{b}$} \\
\hline Mode & $\mathrm{R}$ & R Square & $\begin{array}{l}\text { Adjusted R } \\
\text { Square }\end{array}$ & $\begin{array}{l}\text { Std. Error of } \\
\text { the Estimate }\end{array}$ & $\begin{array}{l}\text { Durbin- } \\
\text { Watson }\end{array}$ \\
\hline 1 & $.786^{\mathrm{a}}$ & .618 & .508 & .55603 & 1.730 \\
\hline
\end{tabular}

Hasil analisisnya adalah (1) Tabel variables entered/removed, tidak terdapat Variables Removed, yang berarti variabel bebas dimasukkan ke dalam perhitungan regresi; (2) R Square pada tabel Model Summary adalah 0,618, yang berarti evaluasi kinerja dapat dipengaruhi oleh tekanan pekerjaan dan stres pekerjaan sebanyak $61,8 \%$ dan sisanya sebesar 38,2\% (100\% - 61,8\%) dipengaruhi oleh faktor lain; (3) Standart error of estimate sebesar 0,55603, di mana semakin kecil standart error of estimate, maka berarti model regresi semakin tepat dalam memprediksi variabel bebas; dan (4) R pada tabel Model Summary adalah 0,786, yang berarti korelasi antara tekanan pekerjaan dan stres pekerjaan dengan evaluasi kinerja sebesar 0,786 .

\section{Analisis Anova dan Koefisien Regresi Sederhana}

Analisis anova dan koefisien regresi sederhana dapat dilihat pada Tabel 15 sebagai berikut.

Tabel 15 Anova and Coefficients

\begin{tabular}{|c|c|c|c|c|c|c|}
\hline \multicolumn{7}{|c|}{ ANOVA $^{b}$} \\
\hline \multirow{4}{*}{$\frac{M}{1}$} & & $\begin{array}{l}\text { Sum of } \\
\text { Squares }\end{array}$ & df & Mean Square & $\mathrm{F}$ & Sig. \\
\hline & Regression & 3.497 & 2 & 1.748 & 5.655 & $.035^{\mathrm{a}}$ \\
\hline & Residual & 2.164 & 7 & .309 & & \\
\hline & Total & 5.661 & 9 & & & \\
\hline
\end{tabular}

a. Predictors: (Constant), Stres_Pekerjaan, Lingkungan_Kerja

b. Dependent Variable: Kinerja_Pengacara

\begin{tabular}{|c|c|c|c|c|c|c|c|c|}
\hline \multicolumn{9}{|c|}{ Coefficients ${ }^{3}$} \\
\hline \multirow[b]{2}{*}{ Madel } & & \multicolumn{2}{|c|}{ Unstandardized Coefficients } & \multirow{2}{*}{$\begin{array}{c}\begin{array}{c}\text { Standardized } \\
\text { Coefficients }\end{array} \\
\text { Beta } \\
\end{array}$} & \multirow[b]{2}{*}{ t } & \multirow[b]{2}{*}{ Siq. } & \multicolumn{2}{|c|}{ Collinearity Statistics } \\
\hline & & B & Std. Error & & & & Tolerance & VIF \\
\hline 1 & (Constant) & 4.530 & 2.460 & & 1.842 & .108 & & \\
\hline & Lingkungan_Kerja & .280 & .394 & .249 & .710 & .500 & .446 & 2.243 \\
\hline & Stres_Pekerjaan & -.595 & .357 & -.583 & -1.666 & 140 & .446 & 2.243 \\
\hline
\end{tabular}

Hasil analisisnya adalah (1) Signifikan di tabel Anova bernilai 0,035, yang $\leq$ dari 0,05, berarti tekanan pekerjaan dan stres pekerjaan berpengaruh terhadap evaluasi kinerja; (2) Hipotesis yakni $\mathrm{H}_{0}$ adalah tekanan pekerjaan dan stres pekerjaan tidak berpengaruh signifikan terhadap evaluasi kinerja dan $\mathrm{H}_{1}$ adalah tekanan pekerjaan dan stres pekerjaan berpengaruh signifikan terhadap evaluasi kinerja; (3) Dasar pengambilan keputusan yakni signifikansi $\geq 0,05$, maka $\mathrm{H}_{0}$ diterima dan signifikansi $\leq 0,05$, maka $\mathrm{H}_{0}$ ditolak; (4) Hasil perhitungannya adalah signifikan bernilai 0,035 , yang $\leq$ dari 0,05 , maka $\mathrm{H}_{0}$ ditolak dan berarti tekanan pekerjaan dan stres pekerjaan berpengaruh terhadap evaluasi kinerja secara signifikan; (5) Persamaan regresi di tabel Coefficient yakni $\mathrm{Y}=4,530+0,280 \mathrm{x}_{1}-0,595 \mathrm{x}_{2}$, di mana $\mathrm{Y}$ adalah evaluasi kinerja, $\mathrm{x}_{1}$ adalah tekanan pekerjaan, dan $\mathrm{x}_{2}$ adalah stres pekerjaan; (6) Pada persamaan regresi di atas, diketahui konstanta sebesar 4,530, menyatakan bahwa jika tidak ada variabel tekanan pekerjaan dan stres pekerjaan, maka evaluasi kinerja nilainya sebesar 4,530; (7) Koefisien regresi sebesar 0,280, menyatakan bahwa setiap penambahan 1 angka, maka variabel tekanan pekerjaan akan menaikkan evaluasi kinerja sebesar 0,280; dan (8) Koefisien regresi sebesar 0, 595, menyatakan bahwa setiap penambahan 1 angka, maka variabel stres pekerjaan akan menurunkan evaluasi kinerja sebesar 0,595 . 


\section{SIMPULAN}

Berdasarkan hasil penelitian atas pengaruh tekanan pekerjaan dan stres pekerjaan terhadap evaluasi kinerja para pengacara di H. Harris Sarana, SH and Partners disimpulkan (1) Variabel tekanan pekerjaan $\left(\mathrm{X}_{1}\right)$ terhadap evaluasi kinerja para pengacara di H. Harris Sarana, SH and Partners sebesar 0,534 . Variabel tekanan pekerjaan mempengaruhi evaluasi kinerja secara signifikan; (2) Variabel stres pekerjaan $\left(\mathrm{X}_{2}\right)$ juga mempengaruhi evaluasi kinerja sebesar 0,590. Variabel stres pekerjaan mempengaruhi kinerja secara signifikan; (3) Besarnya pengaruh dua Variabel bebas (simultan) yaitu pengaruh tekanan pekerjaan $\left(\mathrm{X}_{1}\right)$ dan stres pekerjaan $\left(\mathrm{X}_{2}\right)$ terhadap evaluasi kinerja $(\mathrm{Y})$ adalah sebesar $0,618 \%$ dan mempengaruhi secara signifikan. Berdasarkan kesimpulan di atas, maka saran yang dapat diberikan adalah (1) Karena besarnya pengaruh tekanan pekerjaan terhadap evaluasi kinerja sebesar $53,4 \%$, maka dapat disimpulkan bahwa pengaruh tekanan pekerjaan cukup mempengaruhi evaluasi kinerja. Variabel tekanan pekerjaan dapat mempengaruhi evaluasi kinerja secara signifikan. Dengan keadaan sekarang, pimpinan perusahaan perlu memperhatikan tekanan pekerjaan dan suasana kerja, agar lebih dapat meningkatkan evaluasi kinerja para pengacara; dan (2) Besarnya pengaruh variabel stres pekerjaan terhadap evaluasi kinerja sebesar 59,0\%, maka dapat disimpulkan bahwa variabel stres pekerjaan cukup dominan karena mempengaruhi evaluasi kinerja secara signifikan. Perusahaan perlu memperbaiki sistem komunikasi dan berusaha meminimalisasi segala bentuk stressor kerja, agar para pengacara dapat memberikan hasil yang lebih optimal dalam melakukan pekerjaannya.

\section{DAFTAR PUSTAKA}

Dessler, G. (2004). Manajemen sumber daya manusia, p2,

Kotler. (1997). Pengantar manajemen pemasaran.

Wahyudi, B. (2002). Manajemen sumber daya manusia, p10.

Wardoyo. (2008). Psikologi, p1-2.

Wirawan. (2009). Evaluasi kinerja sumber daya manusia, p3. 